\title{
VINCULAÇÃO AOS PAIS E AO PAR ROMÂNTICO EM ADOLESCENTES
}

\author{
Paula Mena Matos ${ }^{1}$ \\ Maria Emília Costa ${ }^{2}$
}

Resumo: Tomando como ponto de partida a Teoria da Vinculação de Bowlby e Ainsworth e a abordagem conceptual e metodológica de Bartholomew, é apresentado um estudo empírico que pretende analisar (a) as associações entre a vinculação aos pais e a vinculação ao par romântico; e (b) as diferenças de género do adolescente e da figura parental nas representações da vinculação. Os resultados observados com a aplicação de duas entrevistas semi-estruturadas (Family Attachment Interview e Peer Attachment Interview de Bartholomew \& Horowitz, 1991) a uma amostra de 82 adolescentes evidenciam a presença de regularidades nas representações de ambos os domínios, manifestas não apenas em recorrências temáticas e de conteúdo, mas também em recorrências estruturais ao nível da organização discursiva. Ainda que a magnitude dos valores seja moderada, de um modo geral, os adolescentes com vinculações seguras às figuras parentais relacionam-se de um modo mais seguro do ponto de vista romântico, apresentando representações mais favoráveis acerca de si próprio e dos outros. Na generalidade não foram observadas diferenças do género do adolescente nos padrões de vinculação, tendo sido a relação com a mãe classificada como mais preocupada e a relação com o pai como mais desinvestida apenas para os rapazes.

Palavras-chave: vinculação aos pais, relações românticas, adolescência, narrativa

Parental and romantic attachment in adolescents (Abstract): Based on Bowlby's and Ainsworth's attachment theory, and on Bartholomew's conceptual and methodological approach, this paper addresses parental and romantic attachment representations of late adolescents. Using a cross-sectional research design, the study examines (a) continuities and discontinuities across relational domains, and (b) differences in attachment representations as a function of adolescent's and parental gender. Two coded semistructured interviews (Family Attachment Interview e

\footnotetext{
${ }^{1}$ Prof. Auxiliar da Faculdade de Psicologia e de Ciências da Educação da Universidade do Porto.

2 Prof. Catedrática da Faculdade de Psicologia e de Ciências da Educação da Universidade do Porto.

Correspondência sobre este artigo deve ser enviada para pmmatos@fpce.up.pt.
} 
Peer Attachment Interview, Bartholomew \& Horowitz, 1991) were administrated to a sample of 82 late adolescents. Results indicate the presence of regularities in the attachment representations of both domains, evidenced in the thematic and content recurrences, as well as in the structural recurrences of the narratives' organization. Albeit the moderate magnitude of the values observed, adolescents with secure attachments to parents tend to relate in a more secure way to their romantic partners, presenting more positive representations of self and others. No gender differences in attachment patterns were observed, although attachment to mother was classified as more preoccupied for boys and girls, and attachment to father as more dismissive only for boys.

Key-words: attachment to parents; romantic relationships; adolescence; narrative

\section{Introdução}

A construção de novas vinculações durante a adolescência é um processo que tem sido muito pouco aprofundado no plano empírico e sobre o qual a Teoria da Vinculação é relativamente omissa. Se bem que, por diversas ocasiões, Bowlby tenha sublinhado o facto de o sistema de vinculação continuar a ser activado ao longo de todo o ciclo de vida, são poucas as referências na sua obra aos processos e mecanismos que operam a transição em direcção a novas figuras de vinculação, que se inicia de forma mais marcada no período adolescente e que culmina no estabelecimento de uma ligação amorosa que supostamente preencherá todas as funções de vinculação outrora desempenhadas pelas figuras parentais.

A literatura sobre os envolvimentos românticos na adolescência também não abunda e é relativamente recente o reconhecimento deste domínio relacional como potencial contexto desenvolvimental, a par de outros na vida do adolescente (Furman \& Shaffer, 2003; Matos, no prelo). De qualquer modo, a saliência da dimensão romântica na vida do adolescente é indiscutível, sendo, porém, que a natureza e a qualidade das relações românticas dos adolescentes se transformam de acordo com importantes mudanças desenvolvimentais (Bouchey \& Furman, 2003). Neste sentido, em fases mais avançadas da adolescência, a relação romântica começa a desenhar contornos de uma relação de intimidade, de partilha e de mutualidade, onde a necessidade de diferenciação coexiste com a necessidade de ligação emocional ao outro (Costa, 2004).

Mas se a construção deste elo emocional necessita de um maior aprofundamento teórico e empírico, não é menos verdade que, de acordo com a Teoria da Vinculação, as experiências emocionais ocorridas na relação com os pais, e muito particularmente na infância, contribuem decisi- 
vamente para a construção de modelos representacionais acerca de si próprio e do mundo que orientam a acção do sujeito em futuras relações de proximidade emocional (Bowlby, 1973, 1980; Waters \& Cummings, 2000). Dito de outro modo, a história das vinculações com figuras significativas cria expectativas para a relação com os outros e determina estratégias de regulação emocional perante relações de proximidade.

Os estudos empíricos que se têm debruçado sobre este tema têm recorrido, essencialmente, a amostras de jovens adultos e adultos, utilizando diferentes estratégias metodológicas e baseando-se em operacionalizações distintas do constructo da vinculação. Na generalidade, estudos que recorrem a instrumentos de auto-relato e que procuram avaliar retrospectivamente as recordações das figuras parentais apresentam consistência nos seus resultados, apontando para o facto de diferenças na organização da vinculação romântica de jovens e de adultos estarem associadas a representações distintas da qualidade da relação estabelecida na infância com os pais e dos pais entre si. Sujeitos seguros do ponto de vista das suas relações românticas tendem a recordar-se dos seus pais como tendo sido carinhosos, respeitadores, benevolentes, aceitantes e não rejeitantes, menos punitivos, referindo também relações mais carinhosas entre os pais (Collins \& Read, 1990; Diehl, Elnick, Bourbeau \& Labouvie-Vief, 1998; Feeney \& Noller, 1990; Greenberger \& McLaughlin, 1998; Hazan \& Shaver, 1987; Levy, Blatt \& Shaver, 1998; Mikulincer \& Nachshon, 1991; Rothbard \& Shaver, 1994). Por sua vez, os sujeitos evitantes tendem a descrever a mãe como rejeitante e fria, e a figura paterna como não flexível e não razoável, impaciente, instável do ponto de vista emocional, física e emocionalmente indisponível, sentindo-se os jovens alienados na relação com a figura paterna (Rothbard \& Shaver, 1994). Finalmente, os sujeitos ansiosos/ambivalentes tendem a identificar experiências de injustiça, de controle e de intrusividade (Hazan \& Shaver, 1987; Lopez, 1996; Rothbard \& Shaver, 1994).

Numa linha de investigação diferente sobre a qualidade das relações familiares actuais, têm sido observadas associações entre estilos de vinculação seguros e indicadores de coesão, adaptabilidade e satisfação familiar, de acordo com o modelo circumplexo de Olson e colaboradores (Lapsley \& Edgerton, 1998; Mikulincer \& Florian, 1999; Pfaller, Kiselica \& Gerstein, 1998). Os participantes inseguros (tanto ansiosos-ambivalentes como evitantes) percepcionam a família como menos próxima emocionalmente, menos satisfatória e menos capaz de se adaptar às mudanças. Por outro lado, as associações mantêm-se quando se correlacionam as perspectivas dos pais acerca do funcionamento familiar e as representações dos jovens acerca da vinculação romântica, muito embora se desenhem configurações particulares, de acordo com o género da figura parental e do jo- 
vem (Mikulincer \& Florian, 1999). O papel diferencial do género tem, aliás, emergido noutros estudos (Duemmler \& Kobak, 2001; Reese-Weber $\&$ Marchand, 2002), evidenciando-se a necessidade de contemplar no estudo da vinculação a avaliação da relação com cada figura parental separadamente.

Finalmente, uma última linha de investigação procura avaliar a relação entre a vinculação parental e a vinculação romântica, recorrendo essencialmente a entrevistas semi-estruturadas. Com base no sistema de quatro protótipos proposto por Bartholomew e com amostras de jovens adultos, alguns autores observam correlações significativas ( $r$ entre 0,29 e 0,66 ) entre os protótipos idênticos de cada domínio (Bartholomew \& Horowitz, 1991; Bartholomew \& Shaver, 1998). Por sua vez, com base na categorização proposta por Main e colaboradores, outros estudos indicam a presença de classificações semelhantes de segurança ou de insegurança em duas entrevistas (Adult Attachment Interview - AAI; e Current Relationship Interview - CRI) em mais de 60\% dos participantes (Crowell \& Treboux, 2001; Owens, Crowell, Pan, Treboux, O’Connor \& Waters, 1995).

\section{Objectivos e hipóteses}

Um primeiro objectivo deste estudo consiste em observar as relações entre a representação da vinculação à família e a representação da vinculação romântica numa amostra de adolescentes no final do ensino secundário. De acordo com a Teoria da Vinculação e resultados da investigação empírica, parte-se, assim, da hipótese de que existem importantes relações entre a vinculação aos pais e a vinculação romântica e de que, em particular, dimensões de segurança na relação familiar estão associadas a dimensões de segurança na relação com companheiros amorosos. Ou seja, é suposto que adolescentes com relações seguras com os pais se sintam mais confiantes na exploração das relações amorosas com os pares, exibindo comportamentos de vinculação e de prestação de cuidados que promovam a intimidade e a segurança relacional.

A maior parte dos estudos que têm abordado este tema recorre a amostras com participantes de idades mais velhas, sejam estudantes universitários, casais com relacionamentos amorosos duradoiros ou participantes retirados da população geral com um leque de idades alargado. Ora, este critério - o da idade - pode ser especialmente relevante, se tivermos em conta que é a partir do final da adolescência que se assiste ao eclodir de relacionamentos românticos que ganham em significado e em estabilidade no tempo (podendo, como tal, preencher, entre outras, funções de vinculação), começando os sujeitos a ensaiar os equilíbrios possíveis entre a construção da intimidade e a construção da identidade, e a testar a viabilidade 
das representações elaboradas em relações anteriores. Neste sentido, seria esperado assistirmos a uma maior influência dos modelos construídos na relação com os pais sobre os envolvimentos amorosos, uma vez que é suposto a grande maioria dos sujeitos não ter tido ainda uma história de relacionamentos amorosos que lhes permita proceder a alterações substanciais dos modelos representacionais acerca de si próprio e dos outros.

No entanto, crê-se igualmente que a construção de uma vinculação segura a um par possibilita o início de um processo de revisão dos modelos de si próprio e dos outros que orientam a relação com os pais e permite a actualização de novas formas comportamentais, afectivas e cognitivas de relacionamento entre pais e filhos adolescentes. Fica, assim, claro que, na análise das continuidades e descontinuidades que atravessam estes dois contextos relacionais da vida do adolescente, se considera a circularidade e a recursividade das influências. Por outro lado, importa sublinhar o facto de que, no que aos pares diz respeito, o processo de construção de novas vinculações está ainda em curso, continuando as figuras parentais a funcionar como importantes bases de segurança.

É óbvio que este processo de construção e de revisão dos modelos dinâmicos é influenciado pela participação do sujeito em outros contextos de vida, como, por exemplo, a escola e as dinâmicas interpessoais que aí se produzem, bem como o grupo de pares e a comunidade em geral, para além da estrutura social mais alargada, que inevitavelmente limita, em larga medida, os sentidos possíveis deste processo. No que diz respeito ao primeiro aspecto, partilhamos a opinião de alguns autores que consideram que, à medida que os sistemas de vinculação e de prestação de cuidados se tornam mais importantes numa relação amorosa (como é o caso das relações amorosas do final da adolescência e do início da idade adulta), tanto mais será de esperar a influência da relação parental (Furman \& Wehner, 1997), dado ser este o contexto onde, por excelência, estes sistemas foram activados de forma mais significativa. Contrariamente em idades mais jovens em que dominam as motivações afiliativas e de atracção interpessoal e sexual, muito provavelmente a influência das experiências ocorridas na relação com os pares tenderá a ser mais significativa.

Relativamente à importância da organização cultural e das narrativas socialmente dominantes na determinação da acção individual, apenas se salienta que estes não constituem o nível de análise privilegiado neste trabalho, muito embora se reconheça a necessidade da sua articulação com outros determinantes individuais e situacionais para uma compreensão integrada do objecto de estudo em questão.

Um segundo objectivo prende-se com a exploração da existência de determinadas configurações de relações entre as variáveis, consoante o género, quer do adolescente, quer do progenitor. Diversos estudos apontam 
para o facto de os adolescentes representarem de forma diferencial a relação com cada figura parental. Para além disso, em geral, o género dos pais e dos filhos, e a sua articulação em determinados padrões diádicos, tem vindo a revelar-se uma variável importante na compreensão dos efeitos das relações parentais sobre variáveis desenvolvimentais dos adolescentes. Finalmente, algumas teorias reclamam a existência de importantes diferenças de género no modo como são articuladas, ao longo do desenvolvimento, dimensões de autonomia e de ligação emocional (Gilligan, 1982; Josselson, 1987).

Tendo presentes as características da organização social portuguesa e os resultados observados em diferentes estudos empíricos (Buist, Dekovic, Meeus \& van Aken, 2002; Kenny, 1994; Kenny \& Gallagher, 2002; Lopez, 1996; Rice, Cunningham \& Young, 1997), parte-se da hipótese de que existirão diferenças de género do adolescente e da figura parental nas representações da vinculação aos pais. Espera-se que as raparigas representem maior proximidade emocional nas relações com as figuras parentais e designadamente com a mãe, comparativamente com os rapazes. Além disso, espera-se que as raparigas percepcionem a relação com o pai como mais inibidora de movimentos exploratórios, comparativamente com a relação com a mãe. Finalmente, espera-se que, em comparação com a relação com o pai, a relação com a mãe se caracterize por valores mais elevados de vinculação preocupada.

No que concerne à vinculação amorosa, e uma vez que a metodologia de avaliação assenta na abordagem prototípica de Bartholomew, que tem, na generalidade, evidenciado diferenças de género (Bartholomew \& Horowitz, 1991; Brennan, Shaver \& Tobey, 1991; Levy et al., 1998; Scharfe \& Bartholomew, 1994), espera-se que as raparigas apresentem vinculações mais preocupadas relativamente aos seus namorados, e os rapazes vinculações mais desinvestidas.

Finalmente, um terceiro objectivo consiste em observar em que medida a qualidade dos laços emocionais com a família se relaciona com o modo como o adolescente organiza a sua narrativa acerca do relacionamento com os pares. Procura-se, deste modo, abordar a vinculação a partir do conceito de coerência e de organização discursiva (Main, Kaplan \& Cassidy, 1985), partindo-se da hipótese de que uma tarefa essencial da família é apoiar os seus filhos, no processo de construção de sentido, ao longo do seu desenvolvimento. Deste modo, as estratégias de regulação emocional e de comportamento interpessoal evidenciadas nos padrões de vinculação estarão inevitavelmente associadas a configurações particulares dos processos de significação.

No sentido de nos aproximarmos do modo como os adolescentes conferem um sentido pessoal à sua relação com o mundo - do qual os do- 
mínios das relações com os pais e das relações amorosas constituem dois espaços afectivos da maior importância - optámos por uma metodologia que inclui as entrevistas semi-estruturadas, como forma de escutar as histórias que organizam os acontecimentos mais significativas do passado e do presente. Atenderemos, nesta abordagem metodológica, a aspectos estruturais e de conteúdo das narrativas construídas pelos adolescentes.

\section{Método}

\section{Amostra}

A amostra é constituída por 82 participantes, sendo $63,4 \%$ do sexo feminino $(\mathrm{N}=52)$ e $36,6 \%$ do sexo masculino $(\mathrm{N}=30)$. O intervalo de idades varia entre os 17 e os 19 anos, sendo a média de 17,28 anos e o desvio padrão de 0,55 . Todos os adolescentes são provenientes de famílias intactas e vivem com ambos os pais. A maioria destes jovens $(65,9 \%)$ tem um irmão, $15,9 \%$ é filho único e os restantes $(18,2 \%)$ vivem em famílias constituídas por mais de dois filhos. Em média, os pais têm cerca de três anos de escolaridade (DP $=1,75$ ), sendo que $44,4 \%$ dos pais foram classificados no nível ocupacional médio e $33 \%$ no baixo, enquanto que 50,6\% das mães foram classificadas no nível ocupacional baixo e 29,6\% no médio. Note-se que testes $t$ não evidenciaram diferenças significativas em função do género do adolescente, no que diz respeito à escolaridade do pai e da mãe, bem como ao nível ocupacional do pai e da mãe.

Dos adolescentes que realizaram as entrevistas, $12(14,6 \%)$ consideram que nunca tiveram uma relação de namoro significativa. Dos restantes $70(85,4 \%)$, a média de duração da relação mais longa é de 9,58 meses $(\mathrm{DP}=8,47)$, da relação actual é de 10,62 meses $(\mathrm{DP}=9,45)$, sendo que a maioria dos jovens refere ter tido uma a duas relações românticas que considera significativas. Testes $t$ revelaram a não existência de diferenças em função do género, relativamente à duração da relação mais longa, à duração da relação actual e ao número de relações significativas relatadas pelos adolescentes.

\section{Instrumentos}

\section{Entrevista de Avaliação da Vinculação à Família (EVF)}

A Entrevista de Avaliação da Vinculação à Família (EVF) é uma entrevista semi-estruturada, que procura avaliar as representações dos sujeitos acerca das relações familiares à luz da Teoria da Vinculação, na linha da entrevista Adult Attachment Interview, de Main e colaboradores (Bartholomew, 1997), tendo a duração aproximada de 1 hora e 15 minutos. 
Depois de solicitada uma breve descrição acerca de aspectos mais gerais relativos a questões demográficas familiares, o entrevistado é convidado a recuar no tempo e a recordar-se da sua infância, sendo-lhe colocadas questões de acordo com os seguintes temas: momentos de vulnerabilidade e de preocupação; separações; rejeição; perdas, suicídio e terapia; mudanças na relação parental ao longo do tempo e efeitos das experiências infantis no desenvolvimento. Para além destes, é aberta a possibilidade ao entrevistado de recordar outras figuras que tenham sido especialmente significativas ao longo do seu desenvolvimento.

\section{Entrevista de Avaliação da Vinculação aos Pares (EVP)}

A Entrevista de Avaliação da Vinculação aos Pares (EVP) é uma entrevista semi-estruturada, que procura aceder às representações dos participantes relativamente à vinculação no contexto das amizades e no contexto das relações amorosas, dando, porém, particular relevo ao último domínio. A entrevista tem a duração aproximada de 1 hora e 15 minutos, tendo sido administrada neste estudo a terceira versão da autora (Bartholomew, 1996).

Relativamente ao contexto das amizades, o sujeito é convidado a falar primeiro acerca da relação que mantém com um(a) amigo(a) mais próximo(a) e depois acerca das amizades em geral. A segunda parte da entrevista é dedicada, mais extensamente, às relações amorosas e está organizada nos seguintes temas: história das relações amorosas; relação actual; comunicação e apoio; merecimento de amor e de confiança; relação física; resolução de conflitos; mutualidade; separações; arrependimentos e dissolução da relação; finalizando com uma avaliação geral dos relacionamentos do sujeito.

As entrevistas foram traduzidas e adaptadas para o contexto português, tendo em conta, em especial, a relevância e a adequação das questões à idade dos sujeitos a que se destina a sua aplicação neste estudo. Esta tarefa obrigou à realização de alguns ajustamentos, a partir da introdução, omissão ou alteração de algumas questões, tendo-se, igualmente procedido ao acrescento de algumas dimensões na ficha de cotação. Procedeu-se igualmente à tradução do manual da EVP (Matos, Barbosa \& Costa, 1998).

\section{Procedimento de administração}

Os participantes aceitaram voluntariamente participar no estudo, tendo sido contactados aleatoriamente a partir de uma amostra mais alargada de estudantes do $12 .^{\circ}$ ano de escolaridade que haviam respondido a um conjunto de questionários de auto-relato em período anterior. Todas as entrevistas foram gravadas em áudio com a permissão dos participantes, 
tendo sido realizadas em contexto adequado, nas instalações da Faculdade de Psicologia e de Ciências da Educação da Universidade do Porto.

\section{Processo de cotação das entrevistas}

Formação de entrevistadores e juízes

De forma a garantir uma correcta administração das entrevistas e a fiabilidade do respectivo processo de cotação, procedeu-se à formação de entrevistadores e de juízes ao longo de cerca de 6 meses. Para além do conhecimento da Teoria da Vinculação e do modelo de avaliação de vinculação de Bartholomew, os participantes aprofundaram a versão traduzida e adaptada para português do manual, tendo efectuado entrevistas e discutido processos de cotação em grupo. Foram igualmente trabalhados materiais fornecidos por Kim Bartholomew, designadamente transcrições de entrevistas e cassetes áudio, bem como fichas de cotação em que constam também as justificações e reflexões pessoais da autora e de juízes qualificados, tendo sido possível confrontar em grupo as cotações realizadas pelos diferentes membros com a proposta da autora.

A EVF e a EVP são cotadas ao longo de 21 e 27 dimensões, respectivamente, em escalas contínuas de 9 pontos (ver apêndice 1 e 2 para as dimensões). No que toca à entrevista da família, ao contrário do que é habitual, decidiu-se classificar as dimensões relativamente a ambas as figuras parentais e também atribuir classificações separadas quanto ao estilo de vinculação a cada progenitor, face a razões já invocadas anteriormente.

\section{Concordância entre juízes}

Das entrevistas de vinculação à família e aos pares, a grande maioria (77 e 72 entrevistas, respectivamente) foi avaliada por 2 juízes independentes, não tendo existido sobreposição de funções de juiz e de entrevistador, ou seja, cada juiz avaliou apenas as entrevistas que não realizou. Por outro lado, cada domínio relacional foi avaliado separadamente, sendo os juízes cegos relativamente às classificações anteriores. Os desacordos de menor gravidade foram resolvidos em situações de discussão aberta entre os juízes; as situações de desacordo de maior gravidade recorreram à avaliação de um terceiro juiz independente. Também nos casos em que os juízes não chegaram a acordo, mesmo após discussão, as entrevistas foram classificadas por um terceiro juiz.

De acordo com a proposta da autora, procedeu-se, para a avaliação da fidelidade entre juízes, ao cálculo dos coeficientes alpha de Cronbach para todas as dimensões de ambas as entrevistas, uma vez que se tratam de variáveis contínuas. Os valores observados para os protótipos em ambas as 
entrevistas revelam-se adequados, oscilando entre 0,83 e 0,90 e estando de acordo com aqueles observados em outros estudos (Bartholomew \& Horowitz, 1991; Henderson, Bartholomew \& Dutton, 1997; Sharfe \& Bartholomew, 1994, 1995). Das restantes dimensões, a maioria dos valores encontra-se dentro dos parâmetros considerados aceitáveis para o número de itens (ou juízes) em causa, tendo sido retiradas das análises subsequentes as dimensões que não atingiram valores mínimos ${ }^{3}$.

Os processos de testagem da fiabilidade das entrevistas incluíram, ainda, análises de correlações de Pearson entre os protótipos e as dimensões contempladas em cada entrevista, e MANOVAs em função da divisão dos sujeitos pelo estilo dominante 4 . No que diz respeito às correlações entre os protótipos para a vinculação à família, observaram-se correlações negativas entre a segurança e o amedrontamento, tanto na relação com o pai $(r=-0,738 ; p<0,001)$, como na relação com a mãe $(r=-0,729$; $p<0,001)$. No que concerne à vinculação aos pares, observou-se uma correlação negativa entre o estilo seguro e o amedrontado $(r=-0,739$; $p<0,001)$ e uma correlação negativa entre o estilo preocupado e o desinvestido $(r=-0,398 ; p<0,001)$. Por sua vez, da análise correlacional entre as dimensões das entrevistas e as classificações nos protótipos dominantes, é possível concluir que as cotações das entrevistas apresentam coerência interna, ou seja, o sistema de correlações relativamente a cada padrão está de acordo com o esperado teoricamente.

\section{Resultados}

Os resultados serão apresentados em 4 alíneas. Iniciaremos com análises descritivas relativamente às distribuições da vinculação aos pais e aos pares, baseadas nas avaliações categoriais do padrão de vinculação dominante e nas avaliações dimensionais dos padrões de vinculação. De seguida, analisaremos o efeito do género sobre os padrões de vinculação e as dimensões de relacionamento em ambos os domínios relacionais. Apresentaremos também os resultados das análises diferenciais relativas às associações entre a duração da relação amorosa e a vinculação aos pares. Prosseguiremos, em terceiro lugar, com o estudo das associações entre a vinculação aos pais e aos pares, a partir da avaliação da concordância nos

\footnotetext{
${ }^{3}$ É o caso, na vinculação à família, das dimensões "pressão para a realização na relação com a mãe" e "procura de proximidade na relação com o pai", e na vinculação aos pares, das dimensões: "dominância nas relações amorosas", "afectuosidade", "prestação de cuidados" e "insistência em não recordar".

${ }^{4} \mathrm{O}$ estilo dominante é atribuído em função do valor mais elevado obtido nos protótipos.
} 
padrões dominantes e da análise das correlações entre as medidas contínuas da vinculação. Em quarto lugar, abordaremos as dimensões estruturais das entrevistas, a partir do estudo correlacional entre estas e os padrões de vinculação.

Por motivos de clareza da exposição, e dada a quantidade de variáveis em causa, designaremos por: (a) padrão de vinculação dominante, a variável categorial que organiza os sujeitos a partir da classificação mais elevada obtida nas escalas contínuas anteriores, (b) padrões de vinculação, as variáveis contínuas que dizem respeito às classificações atribuídas aos quatro protótipos de vinculação - seguro, preocupado, desinvestido e amedrontado; (c) dimensões do relacionamento parental e com os pares, as variáveis contínuas que serviram de base ao processo de cotação das entrevistas; e (d) dimensões estruturais das narrativas, as variáveis contínuas relativas à organização discursiva dos participantes.

\section{Distribuição das classificações da vinculação aos pais e aos pares}

O Quadro 1 apresenta a distribuição das classificações, de acordo com o padrão dominante de vinculação aos pais e aos pares. É possível constatar que uma percentagem bastante significativa de adolescentes, cerca de $71,5 \%$, é classificada de segura relativamente à vinculação aos pais, sendo que, para além disso, a medida de concordância de Cohen indica que uma percentagem significativa de adolescentes recebeu a mesma classificação para ambos os progenitores $(\mathrm{k}=0,68 ; \mathrm{p}<0,001)$.

Para além disso, assiste-se a uma maior percentagem de adolescentes que foi classificada de preocupada relativamente à mãe (10,8\%), comparativamente com a relação com o pai $(7,2 \%)$. Contrariamente, uma maior percentagem de adolescentes foi classificada de desinvestida relativamente ao pai $(8,4 \%)$, em comparação com aquela que foi considerada na relação com a mãe $(3,6 \%)\left(\chi^{2}(9)=100,864 ; \mathrm{p}<0,001\right)$. No que concerne a vinculação aos pares, a maioria dos adolescentes é classificada como segura $(53,6 \%)$, sendo todavia $24,4 \%$ dos participantes classificados como amedrontados, $12,2 \%$ como preocupados e, finalmente, $9,8 \%$ como desinvestidos.

A leitura do Quadro 1 sugere diferenças nas classificações atribuídas à relação com as figuras parentais e com os pares. Análises do qui-quadrado não apresentam, todavia, diferenças significativas em nenhuma das comparações (mãe/pares e pai/pares). No entanto, testes $t$ para amostras emparelhadas com as variáveis contínuas indicam que os adolescentes obtiveram: (a) valores mais elevados de vinculação preocupada com os pares do que com o pai $(t(81)=4,014 ; p<0,001)$ e com a mãe $(t(81)=2,244 ; p=0,028)$; (b) valores mais elevados de vinculação ame- 
drontada com os pares do que com o pai $(t(81)=6,891 ; p<0,001)$ e com a mãe $(t(81)=6,643 ; p<0,001)$; (c) valores mais elevados de vinculação desinvestida com os pares do que com o pai $(t(81)=2,016 ; p=0,047) \mathrm{e}$ com a mãe $(t(81)=2,837 ; p=0,006)$; e finalmente (d) valores mais baixos de vinculação segura com os pares do que com o pai $(t(81)=-5,647$; $p<0,001)$ e com a mãe $(t(81)=-5,876 ; p<0,001)$.

Quadro 1: Distribuição das classificações da vinculação de acordo com os domínios relacionais e o género

\begin{tabular}{lcccc}
\hline & \multicolumn{4}{c}{ Padrão dominante (\%) } \\
\cline { 2 - 5 } Domínios relacionais & Seguro & Preocupado & Desinvestido & Amedrontado \\
\hline Vinculação à mãe & & & & \\
Raparigas & 69,2 & 11,5 & 5,8 & 13,5 \\
Rapazes & 76,7 & 10,0 & 0 & 13,3 \\
Total & 72,3 & 10,8 & 3,6 & 13,3 \\
Vinculação ao pai & & & & \\
Raparigas & 71,2 & 9,6 & 5,8 & 13,5 \\
Rapazes & 70,0 & 3,3 & 13,3 & 13,3 \\
Total & 71,1 & 7,2 & 8,4 & 13,3 \\
Vinculação aos pares & & & & \\
Raparigas & 46,2 & 15,4 & 9,6 & 28,8 \\
Rapazes & 66,7 & 6,7 & 10,0 & 16,7 \\
Total & 53,6 & 12,2 & 9,8 & 24,4 \\
\hline
\end{tabular}

Efeitos do género e da duração da relação amorosa

Nos padrões de vinculação aos pais e aos pares

O Quadro 1 apresenta, ainda, as distribuições nos padrões de vinculação dominante, de acordo com o género e permite constatar diferenças percentuais na distribuição das classificações. Note-se, em particular, o facto de a amostra não incluir rapazes desinvestidos em relação à mãe, comparativamente com 5,8\% das raparigas. Por sua vez, 13,3\% dos rapazes foram classificados de desinvestidos em relação ao pai, em comparação com apenas 5,8\% das raparigas. Contrariamente, apenas 3,3\% dos rapazes foram classificados de preocupados em relação ao pai, em comparação com 9,6\% das raparigas. Na distribuição relativa à vinculação aos pares existe, no entanto, uma maior aproximação das classificações obtidas em ambas as amostras, no que toca à vinculação desinvestida. De qualquer 
modo, observa-se uma maior prevalência de raparigas preocupadas e amedrontadas e uma maior prevalência de rapazes seguros.

Estas diferenças de género nas distribuições não são, contudo, significativas em nenhum dos domínios relacionais. Todavia, quando se consideram as amostras por género, observam-se diferenças estatisticamente significativas entre as distribuições da vinculação ao pai e à mãe (amostra feminina: $\chi^{2}(9)=71,816 ; p<0,001$; amostra masculina: $\chi^{2}(6)=33,583$; $p<0,001)$. Para além disso, testes $\mathrm{t}$ para amostras emparelhadas com base nas avaliações contínuas dos padrões também indicam que apenas os rapazes são classificados como mais desinvestidos relativamente ao pai por comparação com a mãe $(t(29)=-2,509 ; p=0,018)$. Por sua vez, a vinculação à mãe é classificada como mais preocupada do que a vinculação ao pai, independentemente do género do adolescente $(t(81)=2,798 ; p=0,006)$.

No que diz respeito à vinculação aos pares, realizou-se uma análise de variância multivariada (MANOVA) bifactorial, com o género e a duração da relação amorosa mais longa como factores independentes e os padrões de vinculação como variáveis dependentes. Para o efeito, criaram-se 3 grupos, sendo o primeiro constituído pelos jovens que tiveram uma relação que durou entre 1 a 6 meses $(\mathrm{N}=35)$, o segundo por aqueles que tiveram uma relação que durou entre 7 meses e um ano $(\mathrm{N}=16)$, e o terceiro pelos sujeitos que tiveram uma relação com duração superior a um ano $(\mathrm{N}=18)$. A análise não revelou um efeito de interacção, nem efeitos principais do género e da duração da relação.

Nas dimensões de relacionamento com os pais e com os pares

As MANOVAs detectaram um efeito principal do género apenas no relacionamento com a mãe $(F(16,60)=2,392 ; p=0,008)$, tendo as raparigas obtido valores mais elevados de procura de proximidade $(F(1$, $81)=6,435 ; p=0,013)$ e de ansiedade de separação $(F(1,81)=12,418$; $p=0,001)$, e mais baixos de autonomia $(F(1,81)=5,073 ; p=0,027)$. Também quando se toma em consideração o género da figura parental, os testes $t$ para amostras emparelhadas evidenciaram diferenças significativas para as dimensões responsividade $(t(81)=2,538 ; p=0,013)$, ansiedade de separação $(t(81)=3,972 ; p<0,001)$ e inversão de papéis $(t(81)=3,097$; $p=0,003)$, nas quais os valores relativamente à mãe são superiores aos do pai.

Finalmente, uma MANOVA bifactorial com o género do adolescente e a duração da relação amorosa mais longa como factores e as dimensões do relacionamento com os pares como variáveis dependentes também não evidenciou um efeito de interacção entre ambos os factores, nem do género nem da duração da relação amorosa. 


\section{Relações entre a vinculação aos pais e aos pares}

Concordância nas classificações dominantes

O Quadro 2 indica a concordância entre as classificações da vinculação em ambos os domínios. A medida de Cohen entre a vinculação à mãe $\mathrm{e}$ aos pares revelou-se significativa $(\mathrm{k}=0,20 ; \mathrm{p}=0,004)$, assim como entre a vinculação ao pai e aos pares $(\mathrm{k}=0,21 ; \mathrm{p}=0,020)$. Estes resultados indicam que, ao nível categorial, as classificações da vinculação aos pais estão correlacionadas com a vinculação aos pares, ainda que com uma magnitude baixa. Note-se que, dos 59 sujeitos classificados como seguros na relação com a mãe, 36 receberam a mesma classificação na relação com os pares, ou que, dos 11 adolescentes classificados como amedrontados na relação com a mãe, 5 também o foram com os pares. No entanto, dos 20 adolescentes que obtiveram uma classificação de amedrontados relativamente aos pares, 12 foram classificados de seguros na vinculação à mãe. No total, $54,9 \%$ dos sujeitos obtiveram a mesma classificação em ambos os domínios relacionais, tendo em conta os quatro padrões de vinculação, tanto quando se considera a vinculação à mãe como a vinculação ao pai. Refira-se que as percentagens esperadas pelo acaso são de 43,6\% para a vinculação à mãe e de $43,1 \%$ para a vinculação ao pai.

Quadro 2: Concordância nas classificações da vinculação à mãe e aos pares, e ao pai e aos pares, com base nos quatro protótipos

\begin{tabular}{|c|c|c|c|c|c|c|}
\hline \multirow{3}{*}{$\begin{array}{l}\text { Vinculação à } \\
\text { mãe e ao pai } \\
\text { Seguro }\end{array}$} & \multicolumn{4}{|c|}{ Vinculação aos pares } & & \\
\hline & Seguro & Preocupado & Desinvestido & $\begin{array}{c}\text { Amedronta- } \\
\text { do }\end{array}$ & \multicolumn{2}{|c|}{ Total } \\
\hline & $\begin{array}{cc}37 & 37 \\
(31,7) & (31,3)\end{array}$ & $\begin{array}{cc}5 & 5 \\
(7,2) & (7,1)\end{array}$ & $\begin{array}{cc}5 & 5 \\
(5,8) & (5,7)\end{array}$ & $\begin{array}{cc}12 & 11 \\
(14,4) & (14,1)\end{array}$ & 59 & 58 \\
\hline Preocupado & $\begin{array}{cc}3 & 1 \\
(4,8) & (3,2)\end{array}$ & $\begin{array}{cc}2 & 2 \\
(1,1) & (0,7)\end{array}$ & $\begin{array}{cc}1 & 0 \\
(0,9) & (0,6)\end{array}$ & $\begin{array}{cc}3 & 3 \\
(2,2) & (1,5)\end{array}$ & 9 & 6 \\
\hline Desinvestido & $\begin{array}{cc}1 & 3 \\
(1,6) & (3,8)\end{array}$ & $\begin{array}{cc}1 & 0 \\
(0,4) & (0,9)\end{array}$ & $\begin{array}{cc}1 & 2 \\
(0,3) & (0,7)\end{array}$ & $\begin{array}{cc}0 & 2 \\
(0,7) & (1,7)\end{array}$ & 3 & 7 \\
\hline Amedrontado & $\begin{array}{cc}3 & 3 \\
(5,9) & (5,9)\end{array}$ & $\begin{array}{cc}2 & 3 \\
(1,3) & (1,3)\end{array}$ & $\begin{array}{cc}1 & 1 \\
(1,1) & (1,1)\end{array}$ & $\begin{array}{cc}5 & 4 \\
(2,7) & (2,7)\end{array}$ & 11 & 11 \\
\hline Total & $44 \quad 44$ & $10 \quad 10$ & 88 & $20 \quad 20$ & 82 & 82 \\
\hline
\end{tabular}

Nota: A concordância entre a vinculação à mãe e aos pares encontra-se a letra normal, e entre a vinculação ao pai e aos pares encontra-se a itálico. As frequências esperadas são incluídas entre parênteses. 
Os valores do $k$ de Cohen sobem ligeiramente quando se considera a concordância entre ambos os domínios com base em duas categorias, designadamente o grupo de participantes seguros e o de participantes inseguros $(\mathrm{k}=0,27 ; \mathrm{p}=0,008$, na relação com a mãe; $\mathrm{k}=0,30 ; \mathrm{p}=0,004$, na relação com o pai). No total, $64,6 \%$ dos sujeitos obtiveram a mesma classificação na relação com a mãe e com os pares, e $65,8 \%$ obtiveram a mesma classificação na relação com o pai e com os pares.

Correlações entre os padrões de vinculação.

As associações entre a vinculação aos pais e aos pares foram ainda analisadas a partir das medidas contínuas atribuídas aos padrões de vinculação, com base nas correlações de Pearson. Como é possível observar no Quadro 3, todas as correlações entre os protótipos idênticos em ambos os domínios (assinaladas a carregado) são significativas e variam entre 0,29 e 0,41 , sendo que os valores da vinculação ao pai são superiores aos da vinculação à mãe. Para além disso, observam-se igualmente correlações entre dimensões de vinculação distintas em ambos os domínios. Note-se, em particular, a correlação negativa e moderada entre uma vinculação segura aos pais e a vinculação amedrontada aos pares ( $\mathrm{r}$ médio $=-0,48$ ).

Quadro 3: Correlações de Pearson entre os padrões de vinculação aos pais e aos pares

\begin{tabular}{|c|c|c|c|c|}
\hline \multirow[b]{2}{*}{ Vinculação aos pais } & \multicolumn{4}{|c|}{ Vinculação aos pares } \\
\hline & Seguro & Preocupado & Desinvestido & Amedrontado \\
\hline \multicolumn{5}{|l|}{ Vinculação à mãe } \\
\hline Seguro & $\mathbf{0 , 3 8 0} * *$ & $-0,266^{*}$ & & $-0,462 * *$ \\
\hline Preocupado & $-0,230 *$ & $0,336 * *$ & & $0,242 *$ \\
\hline Desinvestido & & & $0,294 * *$ & \\
\hline Amedrontado & $-0,295 * *$ & & & $0,377 * *$ \\
\hline \multicolumn{5}{|l|}{ Vinculação ao pai } \\
\hline Seguro & $0,413 * *$ & & & $-0,496 * *$ \\
\hline Preocupado & $-0,229 *$ & $0,400 * *$ & $-0,252 *$ & $0,240^{*}$ \\
\hline Desinvestido & & & $0,374 * *$ & \\
\hline Amedrontado & $-0,270 *$ & $0,231 *$ & & $0,380 * *$ \\
\hline
\end{tabular}

Nota: Só estão incluídas as correlações significativas. *p $<0,05 ; * * p<0,01$. A carregado estão as correlações entre padrões idênticos.

$\mathrm{Na}$ generalidade, o padrão de correlações replica na relação com ambas as figuras parentais. Excepções constituem, no caso da vinculação à 
mãe, a correlação negativa entre uma vinculação segura à mãe e preocupada aos pares e, no caso da vinculação ao pai, a correlação negativa entre uma vinculação preocupada ao pai e desinvestida aos pares, e a correlação positiva entre uma vinculação amedrontada ao pai e preocupada aos pares. Finalmente, uma nota para o facto de o sentido das correlações observadas não contrariar o esperado do ponto de vista teórico, isto é, independentemente do domínio em causa, valores de segurança numa relação estão correlacionados positivamente com valores de segurança e negativamente correlacionados com valores de insegurança na outra relação.

\section{Relações entre dimensões estruturais das narrativas e vinculação}

Correlações entre dimensões estruturais da EVF e padrões de vinculação aos pares. Conforme explicitámos anteriormente, do processo de cotação das entrevistas constam, igualmente, dimensões respeitantes à organização e à estrutura do discurso do adolescente. Começámos por analisar as correlações entre dimensões estruturais das narrativas relativamente à família e os valores obtidos nos padrões de vinculação aos pares (Quadro 4).

Quadro 4: Correlações de Pearson entre os padrões de vinculação aos pares e dimensões estruturais das narrativas relativas à família

\begin{tabular}{lcccc}
\hline \multirow{2}{*}{$\begin{array}{l}\text { Dimensões estruturais das } \\
\text { narrativas da família }\end{array}$} & \multicolumn{4}{c}{ Vinculação aos pares } \\
\cline { 2 - 5 } & Seguro & Preocupado Desinvestido & Amedrontado \\
\hline Elaboração & $0,286^{* *}$ & $0,275^{*}$ & $-0,409^{* *}$ & $-0,260^{*}$ \\
Coerência & $0,361^{* *}$ & $-0,251^{*}$ & $-0,331^{* *}$ \\
Integração & $0,324 * *$ & & $-0,352^{* *}$ \\
Insistência em não recordar & & $-0,272^{*}$ & $0,220^{*}$ \\
Idealização & & & \\
mãe & & & $0,308^{* *}$ \\
pai & & & $0,264^{*}$ \\
\hline
\end{tabular}

Nota: Só estão incluídas as correlações significativas. *p $<0,05 ; * * p<0,01$.

Como é possível observar no Quadro 4, a dimensão do amedrontamento na relação com os pares correlaciona-se com todas as dimensões estruturais das narrativas relativas à família, isto é, a elaboração, a coerência, a integração, a insistência em não recordar e a idealização; enquanto que a dimensão do desinvestimento apenas se correlaciona negativamente com a 
elaboração. Por seu lado, a segurança na relação com os pares correlaciona-se positivamente com a elaboração, a coerência e a integração; e a preocupação na relação com os pares correlaciona-se positivamente com a elaboração e negativamente com a coerência e a insistência em não recordar ${ }^{5}$. Finalmente, com a excepção do valor moderado da correlação encontrada entre o desinvestimento e a elaboração, todos os restantes são baixos.

\section{Correlações entre dimensões estruturais da EVP e padrões de vin-} culação aos pais

Prosseguimos com a análise das correlações de Pearson entre dimensões estruturais das narrativas relativas aos pares e os padrões de vinculação aos pais (Quadro 5). Das dimensões avaliadas, a idealização relativa às relações amorosas é, sem dúvida, aquela que mais correlações significativas apresenta com os protótipos de vinculação aos pais. Basicamente, quanto mais preocupados e amedrontados os adolescentes são na relação com os pais, tanto maior a tendência para idealizarem a figura e o relacionamento amoroso. Por sua vez, quanto mais seguros com os pais, tanto menor a idealização no relacionamento amoroso. Note-se que, para além da idealização na relação amorosa, a entrevista permite também a avaliação da idealização nas relações de amizade. Relativamente a esta dimensão, apenas foi encontrada uma correlação entre a vinculação preocupada ao pai e a idealização nas relações de amizade. Para além disso, verifica-se que a idealização da relação amorosa se correlaciona significativamente com outras dimensões do relacionamento com os pais, como as seguintes: rejeição ( $r$ mãe $=0,23 ; p<0,05 ; r$ pai $=0,27, p<0,05)$, raiva na relação paterna $(r$ pai $=0,32, p<0,005)$, inversão de papéis $(r$ mãe $=0,35 ; p<0,005$; $r$ pai $=0,47, p<0,001)$, responsividade por parte do pai $(r$ pai $=-0,25$; $p<0,05)$, consistência de atitudes e comportamentos $(r$ mãe $=-0,23$; $p<0,05 ; \quad r$ pai $=-0,32, p<0,005)$, autonomia ( $r$ mãe $=-0,28 ; p<0,05$; $r$ pai $=-0,31, p<0,005)$ e a qualidade da relação com a mãe $(r$ mãe $=-0,25 ; p<0,05)$.

Note-se, ainda, que a vinculação preocupada aos pais se correlaciona com a elaboração e o riso inapropriado nas entrevistas de vinculação aos pares, enquanto que os adolescentes com uma vinculação desinvestida aos pais tendem a utilizar com mais frequência o "não sei" nas narrativas acerca dos pares. Finalmente, registe-se que apenas a vinculação à figura paterna apresenta uma correlação significativa com a coerência do discurso relativamente aos pares. Quando analisamos a correlação desta última va-

\footnotetext{
${ }^{5}$ Refira-se que por elaboração se entende a capacidade de fornecer uma narrativa detalhada, rica em pormenores, ainda que não necessariamente coerente.
} 
riável com as dimensões de relacionamento com os pais, constatamos uma correlação positiva com a consistência das atitudes paternas $(r=0,22$; $p<0,05)$, e negativa com a inversão de papéis na relação paterna $(r=-0,28 ; p<0,05)$ e com a ansiedade de separação relativa à mãe $(r=-0,25 ; p<0,05)$.

Quadro 5: Correlações de Pearson entre os padrões de vinculação aos pais e dimensões estruturais das narrativas relativas aos pares

\begin{tabular}{|c|c|c|c|c|c|c|}
\hline \multirow[t]{2}{*}{$\begin{array}{l}\text { Vinculação } \\
\text { aos pais }\end{array}$} & \multicolumn{6}{|c|}{ Dimensões estruturais das narrativas dos pares } \\
\hline & $\begin{array}{l}\text { Elabo- } \\
\text { ração }\end{array}$ & $\begin{array}{l}\text { Coerên- } \\
\text { cia }\end{array}$ & $\begin{array}{c}\text { Ideali- } \\
\text { zação } \\
\text { amizade }\end{array}$ & $\begin{array}{c}\text { Idealiza- } \\
\text { ção } \\
\text { relações } \\
\text { amorosas }\end{array}$ & $\begin{array}{l}\text { "Não } \\
\text { sei" }\end{array}$ & $\begin{array}{c}\text { Riso } \\
\text { inapro- } \\
\text { priado }\end{array}$ \\
\hline \multicolumn{7}{|l|}{$\begin{array}{l}\text { Vinculação à } \\
\text { mãe }\end{array}$} \\
\hline Seguro & & & & $-0,297 * *$ & & \\
\hline Preocupado & $0,281^{*}$ & & & $0,353 * *$ & & $0,335 * *$ \\
\hline Desinvestido & & & & & $0,305 * *$ & \\
\hline Amedrontado & & & & $0,280^{*}$ & & \\
\hline \multicolumn{7}{|l|}{$\begin{array}{l}\text { Vinculação ao } \\
\text { pai }\end{array}$} \\
\hline Seguro & & $0,249^{*}$ & & $-0,364 * *$ & & \\
\hline Preocupado & $0,227 *$ & & $0,293 * *$ & $0,420 * *$ & & $0,269 * *$ \\
\hline Desinvestido & & & & & $0,249 * *$ & \\
\hline Amedrontado & & & & $0,292 * *$ & & \\
\hline
\end{tabular}

Nota: Só estão incluídas as correlações significativas. ${ }^{*} \mathrm{p}<0,05 ; * * \mathrm{p}<0,01$.

Correlações entre dimensões estruturais de ambas as entrevistas.

Por fim, analisaram-se as correlações de Pearson entre as dimensões estruturais de ambas as entrevistas, conforme o Quadro 6. A dimensão "riso inapropriado" não se correlacionou significativamente com nenhuma das dimensões da entrevista relativamente à família, pelo que não foi incluída no quadro. A observação do Quadro 6 permite constatar a existência de correlações significativas entre as dimensões estruturais de ambas as entrevistas, consistentes com o esperado do ponto de vista teórico. 
Quadro 6: Correlações de Pearson entre dimensões estruturais de ambas as entrevistas

\begin{tabular}{lcccc}
\hline Vinculação aos pais & \multicolumn{3}{c}{ Vinculação aos pares } \\
\cline { 2 - 5 } & Elaboração & Coerência & $\begin{array}{c}\text { Idealização } \\
\text { relaçóes } \\
\text { amorosas }\end{array}$ & "Não sei" \\
\hline Elaboração & $0,448^{* *}$ & & $-0,472^{* *}$ \\
Coerência & & $0,249^{*}$ & $-0,339^{* *}$ & $-0,234^{*}$ \\
Integração & & $0,265^{*}$ & $-0,245^{*}$ & $-0,404^{* *}$ \\
Insistência em não recordar & $-0,352^{* *}$ & & & $0,477^{* *}$ \\
Idealização & & & $0,231^{*}$ & \\
$\quad$ mãe & & & $0,285^{*}$ & \\
pai & & & & \\
\hline
\end{tabular}

Nota: Só estão incluídas as correlações significativas. *p $<0,05 ; *$ p $<0,01$.

\section{Discussão}

Um dos objectivos centrais deste estudo consistiu em explorar as relações entre a vinculação aos pais e aos pares, partindo da hipótese geral de que a qualidade do relacionamento familiar constitui uma importante fonte de variação individual na natureza dos relacionamentos que os jovens estabelecem com os seus pares e, em particular, com os companheiros românticos. Nas análises conduzidas para a testagem destas relações, foram utilizadas variáveis contínuas e categoriais, reveladoras de dois modos distintos de colocar o problema da avaliação da vinculação. Para além disso, ao considerarmos diversos indicadores no processo de cotação, criámos a possibilidade de entender o constructo de vinculação sob diversos prismas.

Comecemos por considerar a concordância entre a vinculação aos pais e a vinculação aos pares, ao nível categorial, tomando por referência os padrões dominantes. De acordo com o esperado, os resultados indicam que existe uma correspondência entre as classificações atribuídas em ambos os domínios relacionais, muito embora os valores do $k$ de Cohen sejam reveladores de que esta correspondência é apenas moderada, na linha, aliás, do que tem sido observado noutros estudos. Owens et al. (1995) encontraram $64 \%$ dos sujeitos com classificações idênticas na $A A I$ e numa entrevista de avaliação da vinculação aos pares $(C R I)$, tendo por base apenas a distinção entre seguro e inseguro, sendo que este valor desceu para $56 \%$ quando se consideraram quatro grupos de vinculação. Também Crowell e Treboux (2001) verificaram, com uma amostra de casais jovens e com base na classificação em duas categorias, que $67 \%$ dos participantes 
apresenta classificações concordantes a partir das entrevistas acima indicadas. No estudo presente, os valores foram aproximadamente $65 \%$ de correspondências a partir da dicotomia seguro/ inseguro e 54,9\% quando se consideraram os quatro protótipos, valores muito próximos daqueles observados nos estudos anteriores. Mas, para além deste aspecto, importa realçar dois pontos: o primeiro refere-se ao facto de cerca de $36,5 \%$ dos casos classificados de seguros com os pais terem sido classificados de inseguros com os pares, e o segundo diz respeito ao facto de cerca de $30 \%$ dos casos de insegurança na relação com os pais terem sido classificados de seguros com os pares.

O primeiro resultado é especialmente revelador de que o contexto do relacionamento com os pares e as exigências associadas, em particular, à situação amorosa criam situações de vulnerabilidade emocional perante as quais o jovem tem dificuldade em agir, mesmo face a um contexto familiar supostamente caracterizado pela existência de uma base segura. Tendo presente a possibilidade de variabilidade entre os indivíduos classificados num mesmo padrão, aliás, definidora do conceito de protótipo, poderíamos especular em que medida estes jovens, ainda que considerados na globalidade de seguros, apresentariam valores mais elevados de insegurança, na relação com os pais e os pares, em escalas contínuas de vinculação. De qualquer modo, seria interessante despistar se a classificação de insegurança na relação com os pares se manteria no futuro ou se, pelo contrário, ela poderia ser reveladora de circunstâncias específicas do relacionamento amoroso em causa. Pensamos, por exemplo, em situações de perda da figura amorosa ou de abandono da relação, que, imprevistas e/ou contrárias ao desejo do jovem, poderão fazer eclodir sentimentos de vulnerabilidade, que necessitam de tempo para serem integrados construtivamente. Por outro lado, importa também não esquecer que o processo de construção de novas ligações emocionais na adolescência se caracteriza por uma forte componente exploratória, podendo a (in)segurança encontrada nas relações com os pares sofrer importantes oscilações. Este resultado poderá ainda ser interpretado à luz da dinâmica relacional estabelecida no seio da família, aspecto que é dificilmente acedido a partir da consideração da relação diádica entre o adolescente e cada um dos progenitores. De qualquer forma, verificamos que, dos 24 jovens nestas circunstâncias, apenas 5 têm uma vinculação segura a uma das figuras e uma vinculação insegura a outra, enquanto que os restantes apresentam vinculações seguras a ambas as figuras parentais. Na primeira condição, poder-se-ia averiguar em que medida a figura com quem o adolescente tem uma vinculação insegura não desempenhará um papel central no desenvolvimento do adolescente e, em particular, no desenvolvimento de modelos menos positivos acerca de si próprio e dos outros. 
Mas, se o resultado que acabámos de discutir evidencia a descontinuidade entre os contextos de vinculação do jovem, o segundo é, em nossa opinião, especialmente interessante, à luz da Teoria da Vinculação, justamente porque permite a constatação da possibilidade de mudança em direcção à construção de uma relação mais favorável consigo próprio e com os outros, mesmo quando as condições familiares tendem a ser menos apoiantes e seguras. Pese embora a importância da idealização romântica neste período desenvolvimental, poderemos interrogar-nos se o contexto do relacionamento amoroso terá criado situações emocionalmente significativas, que permitiram ao jovem infirmar asserções negativas acerca de si e dos outros, sentindo-se merecedor de amor e confiando no companheiro para a obtenção de conforto e de segurança. Apoiando esta hipótese, estudos prospectivos que procuram avaliar as consequências do apaixonar-se têm evidenciado mudanças significativas ao nível do auto-conceito, do sentido de eficácia pessoal e da estima de si próprio (Aron, Paria \& Aron, 1995). Para além disso, a qualidade da organização da vinculação das figuras românticas poderá revelar-se um factor de importância crucial, potenciando a criação de dinâmicas de segurança no seio da relação romântica.

É óbvio que importa também, mais uma vez, ter em consideração a dinâmica familiar e, em particular, a medida em que uma vinculação segura a pelo menos uma das figuras parentais poderá exercer um efeito protector sobre a qualidade da vinculação aos pares, atenuando a natureza da vinculação insegura à outra figura parental, como, aliás, se constatou a partir dos resultados observados com instrumentos de auto-relato (Matos, 2002). Em todo o caso, no futuro pretende-se efectuar uma análise exploratória das regularidades presentes nas entrevistas deste grupo de jovens, por forma a obter algumas pistas relativas aos mecanismos psicológicos subjacentes a estes eventuais processos de mudança. Para além disso, está em curso um acompanhamento longitudinal que pretende, para além de outros aspectos, testar em que medida os recursos emocionais construídos na relação com os pares contribuem para a reorganização da relação com os pais, tema a que a investigação empírica tem dado muito pouca atenção.

Os resultados obtidos com as classificações categoriais são também apoiados pelas medidas contínuas da vinculação. De acordo com o esperado, existem associações significativas e teoricamente consistentes entre a vinculação aos pais e a vinculação aos pares, do ponto de vista dimensional. É de salientar, em particular, a importância de uma vinculação segura aos pais como meio de prevenir o amedrontamento na relação com os pares. De qualquer modo, comparativamente com o estudo de Bartholomew e Horowitz (1991) que administrou as entrevistas utilizadas no estudo presente, existem algumas diferenças na magnitude dos valores, nomeadamente nos padrões preocupado e desinvestido, em que os valores são supe- 
riores no referido estudo, e no padrão amedrontado, em que o valor é inferior no referido estudo. Recorde-se que os valores encontrados por Bartholomew e Horowitz (1991), numa amostra de 69 estudantes universitários, e com ambas as entrevistas, foram de 0,39 para o padrão seguro, 0,66 para o preocupado, 0,41 para o desinvestido e 0,29 para o amedrontado, não tendo este estudo distingido a vinculação ao pai e à mãe. Todavia, numa segunda amostra de 134 jovens adultos, foram observados valores de 0,37 para o padrão seguro, 0,42 para o preocupado, 0,35 para o desinvestido e 0,46 para o amedrontado, que se aproximam mais daqueles observados no estudo presente, com a excepção do valor encontrado para o padrão amedrontado que, desta vez, é superior no referido estudo.

Tomando por referência os estudos que se baseiam em outros indicadores da qualidade da relação com os pais e a vinculação aos pares, é também possível constatar que os valores encontrados são consistentes com a generalidade dos mesmos (Carnelley, Pietromonaco \& Jaffe, 1994; Diehl et al., 1998; Furman \& Wehner, 1997; Pfaller et al., 1998; Owens et al., 1995).

Contrariamente a resultados encontrados em estudos anteriores com entrevistas semi-estruturadas (Bartholomew \& Horowitz, 1991; Bell, 1998; Kobak \& Sceery, 1988) e às hipóteses formuladas, não foram detectadas diferenças de género do adolescente nos padrões de vinculação ao pai e à mãe, bem como aos pares, tanto numa abordagem categorial como dimensional. No entanto, evidenciaram-se diferenças de género em três dimensões do relacionamento com a mãe, em que as raparigas obtiveram valores mais elevados de ansiedade de separação, de procura de proximidade e mais baixos de autonomia, comparativamente com os rapazes. Por outro lado, em consonância com as hipóteses levantadas e na linha dos resultados observados com instrumentos de auto-relato, as mães surgem como mais responsivas, muito embora a vinculação preocupada, a ansiedade da separação e situações de inversão de papéis sejam igualmente mais frequentes, factos a que não serão alheios aspectos culturais.

De qualquer forma, os resultados traduzem, na globalidade, a inexistência de diferenças substanciais no modo como rapazes e raparigas adolescentes organizam as suas narrativas acerca dos acontecimentos afectivos mais significativos, no domínio das relações com os pais e com os pares, bem como nas estratégias de regulação emocional e de comportamento interpessoal que utilizam nas suas interacções com os outros significativos. Esta tendência para um esbatimento das diferenças de género poderá ser eco de uma cultura que tende cada vez mais a aceitar e a imprimir nas suas práticas um ideal andrógino e a afastar-se da rigidez e da estereotipia associadas à definição de papéis sexuais tradicionais. Refira-se que, num estudo anterior com uma amostra portuguesa de adolescentes, também 
não haviam sido encontradas diferenças de género a partir da entrevista AAI (Soares, 1996). Mas um terceiro conjunto de análises realizadas teve como objectivo testar a hipótese de que vinculações seguras aos pais se relacionam não apenas com os conteúdos narrados pelos adolescentes acerca das suas experiências interpessoais mais significativas, mas também com a estrutura dessas mesmas histórias. Tratou-se, assim, de explorar uma nova dimensão da vinculação, aquela que tem que ver com a organização do discurso acerca de temas e de acontecimentos carregados emocionalmente e com o modo como estes são comunicados no contexto da relação com um estranho, isto é, no contexto interpessoal da entrevista (Main et al., 1985; Oppenheim \& Waters, 1995).

$\mathrm{Na}$ generalidade, os resultados sugerem uma ligação entre a qualidade dos laços emocionais e dimensões estruturais das narrativas, tanto quando se considera a associação entre as dimensões estruturais das narrativas acerca da família e a natureza da vinculação aos pares, como quando se analisa a associação entre qualidade da vinculação aos pais e dimensões estruturais das narrativas acerca do relacionamento com os pares. Dito de outro modo, os diferentes padrões de vinculação não estão apenas relacionados com $o$ que o adolescente narra e privilegia na sua história, mas também com o modo como a sua história se organiza.

Comecemos pelo primeiro ponto, ou seja, a medida em que a capacidade para produzir uma narrativa elaborada, internamente consistente e coerente acerca da família poderá estar associada à qualidade da vinculação aos pares. De facto, os resultados indicam que as propriedades estruturais das histórias que os jovens contam acerca da sua família estão ligadas de forma teoricamente consistente aos relacionamentos com os pares. Assim, verificamos que, quando o jovem é capaz de integrar as experiências emocionalmente significativas ocorridas na história da sua vida familiar, construindo um sentido para a sua relação com a família, as relações com os pares tendem a ser mais seguras. Em sentido contrário, quando se torna difícil compreender os acontecimentos emocionais que ligam o sujeito às figuras de vinculação primárias, quando, apesar de serem escassas as recordações acerca do passado, as figuras tendem a ser idealizadas, quando não parece ser possível construir uma narrativa coerente que dê sentido à existência, então as relações com os pares tendem a ser mais amedrontadas.

Por sua vez, no que toca aos jovens desinvestidos em relação às figuras parentais, verifica-se que, a par do que acontece quando descrevem a sua história familiar, tendem a ser lacunares nas suas descrições dos envolvimentos amorosos e dos relacionamentos com os pares, de um modo geral, refugiando-se, mais do que os outros jovens, no "não sei" ao longo da entrevista, possivelmente revelador de uma exclusão defensiva (Bowlby, 1980). A hipótese mais frequentemente adiantada para a compreensão 
desta atitude considera que a informação associada a acontecimentos penosos tende a ser excluída da consciência e do processamento, prevenindo, deste modo, o confronto com uma matéria susceptível de fazer eclodir emoções com as quais o indivíduo não aprendeu a lidar (Cassidy \& Kobak, 1988; Main, 1990). Parte-se, assim, do princípio de que estes sujeitos terão vivido situações familiares altamente adversas, tendo desenvolvido mecanismos de protecção pessoal, nos quais se incluem a tendência para a idealização das figuras parentais, isto é, a tendência para oferecerem descrições muito favoráveis dos progenitores, sem, todavia, serem capazes de as apoiar com informação episódica e factual acerca dos acontecimentos mais relevantes na história de vida familiar. $\mathrm{O}$ mesmo parece acontecer quando escutamos as entrevistas relativas aos pares, isto é, evidencia-se uma tendência para estes jovens apresentarem um discurso pobre e uma atitude pouco colaborante e envolvida na situação interpessoal da entrevista.

Mas, para além desta hipótese, de difícil operacionalização metodológica, é possível compreender o comportamento destes indivíduos à luz de outras propostas. Alguns autores crêem que este tipo de respostas deriva antes de dificuldades ao nível familiar na comunicação emocional e na ausência da aprendizagem de competências de construção narrativa (Bartholomew, 1990; Oppenheim \& Waters, 1995). Esta explicação descentra a atenção das possíveis situações adversas vividas na infância e com fortes repercussões no desenvolvimento do indivíduo, para os processos de comunicação familiar que favorecem a expressão adequada de emoções e a manutenção de uma memória viva acerca do passado. É, assim, possível que estes indivíduos tenham crescido em famílias que se caracterizam pela ausência de expressividade emocional, mas, simultaneamente, pelo encorajamento da independência e da confiança em si próprio, o que, aliás, explicaria o modelo positivo de si. Saliente-se que a investigação acerca dos supostos mecanismos defensivos presentes nos indivíduos desinvestidos tem vindo a considerar a possibilidade de as estratégias defensivas evidenciadas pelas crianças evitantes (na classificação de Ainsworth) poderem assemelhar-se mais a resultados observados com adultos amedrontados e não tanto com adultos desinvestidos (Fraley, Davis \& Shaver, 1998; Fraley \& Shaver, 1997).

Num sentido contrário, uma vinculação preocupada aos pais parece estar associada à construção de narrativas pormenorizadas acerca da relação com os pares, ainda que muitas vezes estas se distanciem do tópico de conversa e percam em relevância. Por outro lado, também se regista uma maior quantidade de riso inapropriado quando são relatados os acontecimentos com os pares. Além disso, verifica-se que, nas histórias dos jovens preocupados, a figura e a relação amorosa aparecem especialmente idealizadas, isto é, existe um elevado grau de discrepância entre as percepções do jovem acerca das suas relações interpessoais e as inferências que o co- 
tador faz com base nas experiências relatadas. Poderá supor-se, na linha do argumento anteriormente utilizado, que o estilo de comunicação destas famílias possa ser caracterizado por uma elevada expressividade emocional e simultaneamente pela presença de estratégias que ocultam informação relevante ao jovem ou que distorcem as realidades vividas pelos sujeitos, revelando, assim, uma comunicação familiar disfuncional. Recorde-se, a este propósito, que Bowlby (1973), ao longo da sua obra, sublinha a importância de uma comunicação familiar, franca e aberta, acerca das representações de si próprios, da criança e dos outros, que permita o reconhecimento por parte da criança das experiências vividas e a possibilidade de questionar os significados que lhes são atribuídos. As discrepâncias entre as percepções de pais e filhos adolescentes acerca do funcionamento familiar têm vindo, aliás, a revelar-se como preditoras de um menor bem-estar psicológico do adolescente ao longo do tempo (Shek, 1998).

Para finalizar, os valores relativos às associações encontradas entre as dimensões estruturais de ambas as entrevistas são consistentes com o esperado do ponto de vista teórico. Ainda que se observem correlações positivas entre dimensões idênticas em ambos os domínios, é de realçar, nomeadamente, a baixa magnitude do valor relativo à coerência, que é revelador de que, pelo menos na faixa etária contemplada neste estudo, a coerência de cada narrativa é provavelmente bastante influenciada pela natureza e a qualidade das experiências em cada contexto relacional. Doutro modo, se a coerência traduzisse uma propriedade estrutural, seria esperado que a magnitude da correlação fosse mais elevada.

Em síntese, ao reconceptualizar o papel das ligações emocionais ao longo do ciclo de vida, a Teoria da Vinculação oferece uma abordagem conceptual de relevo para o estudo e o aprofundamento dos processos de construção e de dissolução das relações afectivas, que ocorrem não apenas na infância, mas também na adolescência e na idade adulta. Ao privilegiar o final da adolescência, o presente trabalho deu lugar à exploração das representações da vinculação num importante período de transição normativa, permitindo, assim, aprofundar as ligações entre dois contextos de vida significativos - o da relação com as figuras parentais e o da relação com as figuras amorosas.

\section{Referências}

Aron, A., Paria, M., \& Aron, E. N. (1995). Falling in love: Prospective studies of self-concept change. Journal of Personality and Social Psychology, 69, 1102$-1112$.

Bartholomew, K. (1990). Avoidance of intimacy: An attachment perspective. Journal of Social and Personal Relationhips, 7, 147-178. 
Bartholomew, K. (1996). Peer Attachment Interview. (Manuscrito não publicado).

Bartholomew, K. (1997). Adult attachment processes: Individual and couple perspectives. British Journal of Medical Psychology, 70, 249-263.

Bartholomew, K., \& Horowitz, L. (1991). Attachment styles among young adults: A test of a four category model. Journal of Personality and Social Psychology, 61, 2, 226-244.

Bartholomew, K., \& Shaver, P. R. (1998). Methods of assessing adult attachment. Do they converge? In J. A. Simpson \& W. S. Rholes (Eds.), Attachment theory and close relationships (pp. 25-45). New York: Guilford Press.

Bell, K. L. (1998). Family expressiveness and attachment. Social Development, 7, 37-53.

Bouchey, H. A. \& Furman, W. (2003). Dating and romantic experiences in adolescence. In G. R. Adams \& M. D. Berzonsky (Eds.), Blackwell handbook of adolescence (pp. 313-329). Oxford: Blackwell Publishing.

Bowlby, J. (1973). Attachment and loss. Vol. 2: Separation, anxiety and anger. New York: Basic Books.

Bowlby, J. (1980). Attachment and loss. Vol. 3: Loss, sadness and depression. New York: Basic Books.

Brennan, K. A., Shaver, P. R., \& Tobey, A. E. (1991). Attachment styles, gender and parental problem drinking. Journal of Social and Personal Relationships, 8, 451-466.

Buist, K. L., Dekovic, M., Meeus, W., \& van Aken, M. A. C. (2002). Developmental patterns in adolescent attachment to mother, father and sibling. Journal of Youth and Adolescence, 31, 167-176.

Carnelley, K. B., Pietromonaco, P. R., \& Jaffe, K. (1994). Depression, working models of others, and relationship functioning. Journal of Personality and Social Psychology, 66, 127-140.

Cassidy, J., \& Kobak, R. R. (1988). Avoidance and its relation to other defensive processes. In J. Belsky \& T. Nezworski (Eds.), Clinical implications of attachment (pp. 300-323). Hilldsdale, N. J.: Erlbaum Publ.

Collins, N. L., \& Read, S. J. (1990). Adult attachment, working models, and relationship quality in dating couples. Journal of Personality and Social Psychology, 58, 644-663.

Costa, M. E. (2004). The development of intimacy during adolescence. Conferência apresentada na IX Conference of the Association for Research on Adolescence, Porto, Portugal.

Crowell, J. A., \& Treboux, D. (2001). Attachment security in adult partnerships. In C. Clulow (Ed.). Adult attachment and couple psychotherapy (pp. 28-42). London: Brunner-Routledge.

Diehl, M., Elnick, A. B., Bourbeau, L. S., \& Labouvie-Vief, G. (1998). Adult attachment styles: Their relations to family context and personality. Journal of Personality and Social Psychology, 74, 1656-1669.

Duemmler, S., \& Kobak, R. (2001). The development of commitment and attachment in dating relationships: attachment security as a relationship construct. Journal of Adolescence, 24, 401-415. 
Feeney, J. A., \& Noller, P. (1990). Attachment style as a predictor of adult romantic relationships. Journal of Personality and Social Psychology, 58, 281-291.

Fraley, R. C., \& Shaver, P. R. (1997). Adult attachment and the suppresion of unwanted thoughts. Journal of Personality and Social Psychology, 75, 1198$-1212$.

Fraley, R. C., Davis, K. E., \& Shaver, P. R. (1998). Dismissing-avoidance and the defensive organization of emotion, cognition and behavior. In J. A. Simpson \& W.S. Rholes (Eds.), Attachment theory and close relationships (pp. 249-279). New York: Guilford Press.

Furman, W., \& Shaffer, L. (2003). The role of romantic relationships in adolescent development. In P. Florsheim (Ed.), Adolescent romantic relations and sexual behaviour: Theory, research, and practical implications (pp. 3-22). Mahwah: Lawrence Erlbaum Associates, Publishers.

Furman, W., \& Wehner, E. A. (1997). Adolescent romantic relationships: A developmental perspective. In S. Shulman \& W. A. Collins (Eds.), Romantic relationships in adolescence: Developmental perspectives. New Directions for Child Development, 78, 21-36.

Gilligan, C. (1982). In a different voice: Psychological theory and women's development. Cambridge, Massachusetts: Harvard University Press.

Greenberger, E., \& McLaughlin, C. S. (1998). Attachment, coping, and explanatory style in late adolescence. Journal of Youth and Adolescence, 27, 121-139.

Hazan C., \& Shaver, P. (1987). Romantic love conceptualized as an attachment process. Journal of Personality and Social Psychology, 52, 511-524.

Henderson, A. J. Z., Bartholomew, K., \& Dutton, D. G. (1997). He loves me; He loves me not: Attachment and separation resolution of abused women. Journal of Family Violence, 12, 169-191.

Josselson, R. (1987). Finding herself: Pathways to identity development in women. San Francisco: Jossey-Bass.

Kenny, M. E. (1994). Quality and correlates of parental attachment among late adolescents. Journal of Cousneling and Development, 72, 399-403.

Kenny, M. E., \& Gallagher, L. A. (2002). Instrumental and social/relational correlates of perceived maternal and paternal attachment in adolescence. Journal of Adolescence, 25, 203-219.

Kobak, R. R., \& Sceery, A. (1988). Attachment in late adolescence: Working models, affect regulation and representations of self and others. Child Development, 59, 135-146.

Lapsley, D. K., \& Edgerton, J. (1998). Pathological and normal separation-individuation in late adolescence: Implications for adult attachment and college adjustment. Comunicação apresentada no Biennial Meeting of the Society for Research on Adolescence. San Diego.

Levy, K. N., Blatt, S. J., \& Shaver, P. R. (1998). Attachment styles and parental representations. Journal of Personality and Social Psychology, 74, 407-419.

Lopez, F. G. (1996). Attachment-related predictors of constructive thinking among college students. Journal of Counseling \& Development, 75, 58-63. 
Main, M. (1990). Cross-cultural studies of attachment organization: Recent studies, changing methodologies, and the concept of conditional strategies. Human Development, 33, 48-61.

Main, M., Kaplan, N., \& Cassidy, J. (1985). Security in infancy, childhood and adulthood: A move to the level of representation. In I. Bretherton \& E. Waters (Eds.), Growing points in attachment theory and research. Monographs of the Society for Research in Child Development, 50, (1-2, Serial Nr. 209), 66-104.

Matos, P. M. (2002). (Des)continuidades na vinculação aos pais e ao par amoroso em adolescentes. Tese de doutoramento apresentada à Faculdade de Psicologia e de Ciências da Educação da Universidade do Porto.

Matos, P. M. (no prelo). Relações românticas em adolescentes. Psychologica.

Matos, P. M., Barbosa, S., \& Costa, M. E. (1998). Manual da entrevista de vinculação aos pares de K. Bartholomew e documentos adicionais. Material policopiado (p. 88). Porto: ICPFD.

Mikulincer, M., \& Florian, V. (1999). The association between parental reports of attachment style and family dynamics, and offspring's reports of adult attachment style. Family Process, 38, 243-257.

Mikulincer, M., \& Nachshon, O. (1991). Attachment styles and patterns of self-disclosure. Journal of Personality and Social Psychology, 61, 321-331.

Oppenheim, D., \& Waters, H. S. (1995). Narrative processes and attachment representations: Issues of development and assessment. In E. Waters, B. Vaughn, G. Posada \& K. Kondo-Ikemura (Eds.), Caregiving, cultural and cognitive perspectives on secure-base behavior and working models. Monographs of the Society for Research in Child Development, 60 (2-3, Serial Nr. 244), 197-215.

Owens, G, Crowell, J. A., Pan, H., Treboux, D., O'Connor, E., \& Waters, E. (1995). The prototype hypothesis and the origins of attachment working models: Adult relationships with parents and romantic partners. Monographs of the Society for Research in Child Development, 60 (2-3, Serial Nr. 244), 216-233.

Pfaller, J., Kiselica, M., \& Gerstein, L. (1998). Attachment style and family dynamics in young adults. Journal of Counseling Psychology, 45, 353-357.

Reese-Weber, M., \& Marchand, J. F. (2002). Family and individual predictors of late adolescents' romantic relationships. Journal of Youth and Adolescence, 31, 197-2006.

Rice, K. G., Cunningham, T. J., \& Young, M.B. (1997). Attachment to parents, social competence, and emotional well-being: A comparison of black and white late adolescents. Journal of Counseling Psychology, 44, 89-101.

Rothbard, J., \& Shaver, P. (1994). Continuity of attachment across the life span. In M. Sperling \& W. Berman (Eds.), Attachment in adults (pp. 31-71). N.Y.: The Guilford Press.

Sharfe, E., \& Bartholomew, K. (1994). Reliability and stability of adult attachment patterns. Personal Relationships, 1, 23-43.

Sharfe, E., \& Bartholomew, K. (1995). Accomodation and attachment representations in young couples. Journal of Social and Personal Relationships, 12, 380-401 . 
Shek, D. T. L. (1998). A longitudinal study of Hong-Kong adolescents' and parents' perceptions of family functioning and well-being. The Journal of Genetic Psychology, 159, 389-403.

Soares, I. (1996). Representação da vinculação na idade adulta e na adolescência. Estudo intergeracional: Mãe-Filho(a). Braga: Universidade do Minho, Instituto de Educação e Psicologia.

Waters, E. \& Cummings, E. M. (2000). A secure base from which to explore close relationships. Child Development, 71, 164-172.

Apêndice 1: Variáveis relativas à entrevista de avaliação da vinculação à família

\section{Dimensões do relacionamento com os pais Dimensões estruturais das narrativas}

$\begin{array}{ll}\text { Responsividade/Sensibilidade* } & \text { Elaboração } \\ \text { Encorajamento da exploração* } & \begin{array}{l}\text { Coerência } \\ \text { Rejeição* }\end{array} \\ \text { Pressão para a realização* } & \begin{array}{l}\text { Integração } \\ \text { Consistência em }\end{array} \\ \text { Procura de proximidade e apoio* } & \text { Idealização* } \\ \text { Ansiedade de separação* } & \\ \text { Raiva/revolta em relação aos pais* } & \text { Protótipos de } \\ \text { Autonomia* } & \text { Seguro* } \\ \text { Inversão de papéis* } & \text { Preocupado* } \\ \text { Qualidade da relação* } & \text { Desinvestido* }\end{array}$

Nota: Todas as dimensões assinaladas com * são avaliadas separadamente para cada figura parental. 
Apêndice 2: Variáveis relativas à entrevista de avaliação da vinculação aos pares

\begin{tabular}{|c|c|}
\hline $\begin{array}{l}\text { Dimensões relativas ao domínio das amiza- } \\
\text { des }\end{array}$ & Dimensões estruturais das narrativas \\
\hline Self-disclosure & Elaboração \\
\hline Envolvimento relativo & Coerência \\
\hline Dominância & Insistência em não recordar \\
\hline Qualidade da relação com o sexo oposto & Riso inapropriado \\
\hline Qualidade da relação com o mesmo sexo & "Não sei" \\
\hline Qualidade global das relações & Idealização das relações de amizade \\
\hline $\begin{array}{l}\text { Dimensões relativas ao domínio das rela- } \\
\text { ções amorosas }\end{array}$ & $\begin{array}{l}\text { Idealização das relações amorosas } \\
\text { Idealização geral }\end{array}$ \\
\hline & Protótipos de vinculação \\
\hline \multicolumn{2}{|l|}{ Self-disclosure } \\
\hline \multicolumn{2}{|l|}{ Envolvimento relativo } \\
\hline Dominância & Seguro \\
\hline Base segura & Preocupado \\
\hline Situação de abuso & Desinvestido \\
\hline Qualidade das relações & Amedrontado \\
\hline \multirow{2}{*}{ Dimensões globais } & Informações adicionais \\
\hline & Padrão de choro \\
\hline Procura de proximidade & Duração da relação mais longa \\
\hline Expressividade emocional & Duração da relação actual \\
\hline Dependência emocional & Nível de envolvimento \\
\hline Prestação de cuidados & Número de relações significativas \\
\hline Afectuosidade & \\
\hline Ciúme & \\
\hline Ansiedade de separação & \\
\hline Confiança no outro & \\
\hline Autoconfiança & \\
\hline
\end{tabular}

